\title{
$\angle S$ Research Square \\ Incidence and risk factors for tuberculosis among people living with HIV in Bangui: a cohort study
}

\section{Jean De Dieu Longo}

Research and Intervention Unit on Sexually Transmitted Diseases and AIDS and AIDS, Department of

Public Health, Faculty of Health Sciences, Bangui, Central African Republic

\section{Sylvain Honoré Woromogo ( $\square$ woromogos@gmail.com )}

Inter State Centre of Higher Education in Public Health of Central Africa

\section{Henri Saint-Clavaire Diemer}

National Reference Centre for Sexually Transmitted Diseases and Antiretroviral Therapy, Bangui, Central African Republic

\section{Gaspard Tékpa}

Research and Intervention Unit on Sexually Transmitted Diseases and AIDS and AIDS, Department of Public Health, Faculty of Health Sciences, Bangui, Central African Republic

\section{Laurent Belec}

Georges Pompidou European Hospital, Paris Public Hospitals, Université Paris Descartes

\section{Gérard Grésenguet}

Research and Intervention Unit on Sexually Transmitted Diseases and AIDS and AIDS, Department of Public Health, Faculty of Health Sciences, Bangui, Central African Republic

\section{Research Article}

Keywords: incidence, tuberculosis, HIV, quality of care, Bangui

Posted Date: February 16th, 2022

DOI: https://doi.org/10.21203/rs.3.rs-1353660/v1

License: (c) (1) This work is licensed under a Creative Commons Attribution 4.0 International License. Read Full License 


\section{Abstract}

Background. Tuberculosis-HIV co-infection is the leading cause of death for people living with HIV (PLHIV) in the Central African Republic. The objective of this study was to determine the incidence and risk factors of TB among PLHIV in Bangui.

Methods: This was a retrospective study carried out on a cohort of PLHIV followed in an HIV infection management center in Bangui. PLHIV aged 18 or older, with no history of TB, enrolled between January 1 , 2017 and December 31, 2018 were included in the study. The software, Epi Info 7, made it possible to enter and analyze the data. The chi-square test was used only to compare the proportions at the $5 \%$ significance level.

Results: A total of 677 patients including 618 (91.28\%) on antiretroviral therapy were included in the study. The median age was 34 with extremes ranging from 18 to 57 . Of the patients followed, 104 developed TB. The overall incidence of TB was 15.37 (104/677) cases per 100 PLHIV-years. This incidence was $13.10(81 / 618)$ cases per 100 in patients on ART-years and 38.99 (23/59) cases per 100 patients on pre-ART-years. In pre-ART patients the incidence of TB was therefore almost 3 times higher than that of PLHIV on ART ( $p=0.03)$. WHO clinical stages III and IV $(p=0.02)$, absence of ART $(p=0.03)$, poor adherence $(p=0.004)$ and low functional capacity $(p=0.04)$ were the risk factors associated with the occurrence of TB among PLHIV in Bangui.

Conclusions: The high incidence of TB in our context is essentially linked to delay in diagnosis and the quality of care. Early initiation of antiretroviral therapy, systematic screening for TB in PLHIV upon entry into the active queue and better monitoring of patients on ART are strongly recommended.

\section{Background}

Controlling the TB epidemic is a major challenge for public health programmes in African countries. HIV infection has increased the burden of TB, especially in populations with high prevalence of TB, mainly in sub-Saharan Africa and South East Asia [1]. HIV co-infection is the main cause of increased mortality risk in TB. The incidence of TB is particularly high in sub-Saharan Africa, reaching 259 cases per 100,000 inhabitants. The overall mortality rate is $23 \%$ and even exceeds $50 \%$ in the African countries most affected by HIV infection [1]. The incidence of TB among AIDS patients ranges from 20 to $40 \%$ [1; 5-7]. It can reach $80 \%$ in countries with high HIV seroprevalence [2]. Of the approaches needed to assess the interference of the two endemics, HIV infection and TB, incidence and prevalence are the most important parameters $[5 ; 6]$.

The Central African Republic is a country highly affected by both diseases. The prevalence of HIV infection is estimated at $4.9 \%$ among adults aged $15-49$ years [1] and the country reports national coverage of antiretroviral (ARV) treatment at $40 \%$ at the end of 2018 [2]. Screening for HIV infection is often delayed and case management does not systematically take into account underlying tuberculosis. Thus, the incidence of TB in PLHIV is not regularly documented, but the global report on TB in CAR 
published by the WHO in 2016 gives an incidence of 400 cases per 100,000 inhabitants without distinction of serological status [2]. The targeted objectives of this study were to determine the incidence and identify the risk factors of TB among PLHIV followed in Bangui, in order to propose adapted strategies for a better control of the disease.

\section{Methods}

\section{Setting, type and period of study}

This study took place at the National Reference Centre for Sexually Transmitted Infections and Antiretroviral Therapy (CNRISTTAR) in Bangui, which is a reference centre for the care of PLHIV in the Central African Republic. The CNRISTTAR is a centre with an active file of 4,940 PLHIV, i.e. $21.1 \%$ $(4,940 / 2,3412)$ of registered PLHIV in Bangui. The active file of patients on ARVs is 3142 , i.e. $13.4 \%$ of the active file in Bangui. The choice of this study site was motivated by the good quality of services offered to PLHIV $[3,4]$ and the existence of an electronic and physical database. This was a retrospective study. The duration of the study (inclusion and all follow-ups) was two years.

\section{Sampling, inclusion and follow-up time of patients}

The study population consisted of all PLHIV enrolled in CNRISTTAR for medical management. We included all PLHIV aged at least 18 years, enrolled between January 2016 and December 2017, free of TB at initiation and followed for 2 years. Routine TB screening at enrolment of PLHIV was based on clinical criteria. Patients with incomplete records were not included in the study. We considered any patient with a positive bacilloscopy, culture or molecular test (Xpert MTB/RIF®) as a TB case.

\section{Variables}

Information collected for each patient included socio-demographic (age and sex), clinical (Body Mass Index or BMI, WHO clinical stages, type of TB, clinical diagnosis of TB, antiretroviral treatment, functional capacity and adherence to treatment) and paraclinical characteristics (CD4 count, sputum microscopy. The incidence rate is the number of new TB cases divided by the number of PLHIV multiplied by the risk period.

\section{Data collection, processing and management}

A data collection form was designed to record information on each patient. The collection of information was based on the record of ARV treatment and the record of TB treatment. All patient data were anonymized before entry.

\section{Data analysis}

Excel $2007 \AA$, Epi Info $7 \odot$ and SPSS $\AA$ version 20 were used to analyze the data. The Pearson Chi-square test with a significance level of $5 \%$ was used to compare categorical variables. To determine the risk 
factors, we calculated the crude relative risk (bivariate analysis) and the Cox regression adjusted hazard ratio (multivariate analysis).

\section{Ethical considerations}

The survey was granted clearance No16/UB/FACSS/2016. Data collection was done in strict compliance with the Declaration of Helsinki.

\section{Results}

\section{Characteristics of PLHIV at inclusion}

Over the period of our study (January 2016 to December 2017), we reviewed 866 records. Of these 866 records, we excluded 189 or 21.8 who did not meet the inclusion criteria. A total of 677 patients were included in the study. Females predominated with $71.6 \%(n=485)$ of cases. Approximately $91.3 \%(n=618)$ of the patients were on antiretroviral therapy versus $8.7 \%(n=59)$ who were waiting for treatment.

\section{Incidence of TB}

Of the 677 patients included in the study, 104 developed TB disease. The overall TB incidence rate was therefore 7.7 per 100 PLWHA-years. This incidence is 19.50 per 100 PLHIV pre-ART year, about 2.5 times the incidence in PLHIV on ART (Table 1). The median age of the PHAs who developed TB was 34 years (range 18 - 57 years), with females predominating (65.4\%). More than half of the PLHIV who developed TB were in WHO stage III (Figure 1, Table 1). Of the 618 PLHIV on ART, 81 (13.1\%) developed TB, 41 $(50.7 \%)$ during the first trimester of follow-up. Among the 59 patients on pre-ART, 23 (38.98\%) developed TB, 8 (34.78\%) of them during the first quarter (Figure 2). Table 2 shows a slightly high incidence of TB in younger PLHIV (18 - 44 years), male PLHIV, PLHIV with CD 4 \350 and in those with poor adherence. However, it was very high in WHO stage III and IV PLHIV, PLHIV waiting for antiretroviral treatment and in PLHIV who had lost weight and/or were bedridden.

\section{Characteristics of PLHIV who developed TB}

Of the 104 PLHIV who developed TB, the median age was 34 years with extremes ranging from 18 to 57 years. As in the original population, the majority were female. More than half of the PLWH who developed TB were at an advanced stage (III or IV) with a mean CD4 count of $272 / \mathrm{mm} 3$ and a median of $229 / \mathrm{mm} 3$. In our series, microscopy-positive pulmonary TB was the most frequent $(61.54 \%, n=64)$, followed by microscopy-negative pulmonary TB $(25 \%, n=26)$ and extra-pulmonary TB $(13.46 \%, n=14)$.

\section{Risk factors for the occurrence of TB in PLHIV}

Young age and gender with all an RR 1 ; but not significant ( $p \otimes 0.05)$ are not risk factors for TB. There is no risk of TB in older PLHIV (RR=0.93, $p=0.41)$ and those with low CD4 counts ( $R R=0.75, p=0.09)$. On the 
other hand, the risk of TB is higher in WHO stage III and IV PLHIV (RR=21.96, $\mathrm{p} \otimes 0.05)$, pre-ART patients $(R R=2.97, p \otimes 0.05)$, patients with poor adherence $(R R=3.66, p \otimes 0.001)$ and those who have lost weight.

\section{Discussion}

PLHIV at all stages have developed TB. The incidence of TB is 7.68 cases per 100 PLHIV year. Incident cases are high in patients aged 18 to 44 years (15.74 per 100 PLHIV-year), men (18.75 per 100 PLHIVyear) and patients with a CD4 less than $350 / \mathrm{mm} 3$ (19.01 per 100 PLHIV-year). This incidence is very high in non-adherent patients (28.57 per 100 PLHIV-years), pre-ART patients (38.99 per 100 PLHIV-years), WHO stage III and IV patients (61.80 per 100 PLHIV-years) and patients with weight loss (94.28 per 100 PLHIVyears). Among PLHIV on ARVs, half of the incident cases ( $n=41 / 81$, or $50.7 \%$ ) occurred during the first trimester of follow-up. WHO clinical stages III and IV, lack of ART, poor adherence and weight loss were the risk factors for TB in PLHIV.

This study has limitations. The first difficulty of this study is related to missing data due to its retrospective nature. However, even though the follow-up time was not long, almost a quarter of the HIVinfected patients ( $n=144$ or $21.27 \%$ ) had enrolled for treatment when they were already in stage III and IV of the disease. At the time of data collection, information on the weight of patients was well documented; however, data on the height of patients was only partially available. This did not allow us to take into account the body mass index in the study of risk factors. Therefore, information on dietary habits (tobacco and alcohol) as risk factors was not collected from PLHIV. PLHIV in communal settings (prisons, IDP sites and others) have a higher risk of developing TB than those living outside these settings $[5,6]$. We did not have sufficient information on the place of residence or occupation, or the level of education. However, according to the literature, precariousness, other infectious diseases, alcoholism and chronic illnesses are all factors that contribute to the lowering of the immune system and can influence the extra pulmonary spread of TB $[5,6]$.

The incidence of TB, which was high in patients on ART in the first quarter of treatment, declined over time (Figure 2). We believe that the risk of contracting TB in PLHIV decreases as the time to start ART increases. Koch's bacillus (KB) is most likely already present but quiescent even before HIV infection in a hyper-endemic TB country like CAR.

The delay in ARV treatment probably facilitates the clinical expression of BK. The high annual incidence of TB and the predominance of the pulmonary form can be explained by the high prevalence of TB in CAR, which is predominantly pulmonary between 2008 and 2012 (data from the National TB Control Programme, 2012 Review, CAR). This high incidence of TB among PLHIV during the first quarter of ART is in line with the results of studies conducted in Côte d'Ivoire [7], Burkina Faso [8-10], South Africa [11,12], Uganda [13], Niger [14], and the study by Bonnet et al. conducted in five countries (Cambodia, Thailand, Kenya, Malawi and Cameroon) [15]. This high incidence of TB thus reflects the need to introduce isoniazid preventive treatment among PLHIV in CAR as soon as ARVs are introduced. The deflation of incidence as one moves away from the date of ART initiation was also reported by Foucher and 
colleagues in Niger, who found a regressing incidence (5\%) after 6 months of ARV treatment [14]. Dembélé et al. in Burkina Faso reported the same for the decrease in incidence with 2.23 per 100 people after 180 days, 1.21 per 100 people after 365 days and 0.18 per 100 people after 365 days [9]. The restoration of the immune system induced by antiretroviral treatment could explain the decline in TB incidence [16]. In contrast, in Uganda, the incidence of TB in one cohort remained high beyond 365 days (2.18 per 100 PLHIV) after initiation of highly active antiretroviral therapy [13]. The high prevalence of HIV, known in the literature as an aggravating factor in TB, would explain this situation in this country [13]. WHO clinical stages III and IV, delay in ARV treatment and low body mass index (BMI $\leq 18.5$ ) or wasting, considered as risk factors in our study, have also been reported in studies conducted in Niger, South Africa, Burkina Faso and Uganda [8-14]. Low CD4 T-cell count as a risk factor in some African studies was not identified as a risk factor in our results $[9,14,15]$. Male sex was considered a risk factor in the studies by Poda et al in Burkina Faso [8]. In our study the risk was not significant ( $R R=1.33, p=0.06)$. Nationally, as in our study, the female sex among all PLWH was predominant (data from the National TB Control Programme, 2012 Review, CAR) and the most affected by TB among the 104 PLWH. In contrast to our data where female HIV-TB co-infected patients were predominant, male predominance of coinfections was reported in studies conducted in Africa [9,17-19] and Brazil [20,21]. The slightly higher incidence of TB in men than in women is consistent with the findings of Dembélé and colleagues [9]. Incident TB cases in patients with CD4 less than 350/mm3 were higher than in patients with high CD4 $(\varangle 350 / \mathrm{mm} 3)$; this is consistent with the literature $[9,14]$. The majority of PLWH had TB in WHO stages III and IV combined (85.58\%), a result comparable to previous studies [9,14]. Patients with less advanced WHO stages (I and II) reported TB. This reflects the fact that due to immunosuppression, TB can occur at any stage of the disease [22]. The predominance of microscopy-positive pulmonary TB (MPT+), followed by microscopy-negative pulmonary TB (MPT-) and extra pulmonary TB (EPT), respectively, is in line with national NTP data from 2008 to 2012, which place MPT+ in first position, followed by MPT- and EPT. Similar results have been found in Africa $[10,17,23,24]$, in contrast to studies in Niger which showed a predominance of EPT $[14,24]$.

The incidence of TB in pre-ART PLHIV was almost 3 times higher than that of PLHIV on ART. According to WHO, in the context of monitoring TB/HIV activities, access to ARVs can reduce the incidence of TB in PLHIV by $50-80 \%$. Similarly, isoniazid preventive treatment when given to PLHIV without active TB reduces the incidence of TB by $50 \%$ (WHO Collaborative Guide for TB/HIV Activities 2004). The incidence of TB in a study by Dembelé et al. in Burkina Faso where all PLWH were on highly active antiretroviral therapy was lower than ours [9]. In our study the majority of pre-ART patients developed WHO stage III TB. The incidence of TB is high in this pre-ART group although they are less numerous than PLWHA on ART. The absence of ART in some PLWHA (59 or $8.71 \%$ ) and the advanced WHO stage would explain this high incidence of TB at the Bangui CNRISTTAR.

\section{Conclusion}

Our data showed that PLHIV develop TB at all WHO clinical stages. The incidence of TB is high in patients waiting for ART, PLHIV in advanced WHO stages, those with weight loss and in the first trimester 
of ART treatment. Emphasis should be placed on initiating ART at earlier stages of the disease and systematically screening PLHIV for TB at entry. This study has highlighted the need to introduce isoniazid preventive treatment in PLHIV before they are started on ARVs. The aspects mentioned in the limits of this study must be taken into account not only for a better management of the CNRISTTAR database, but also for an improvement in the quality of patient care at the center.

\section{Declarations}

Ethics approval and consent to participate: The survey was granted clearance No16/UB/FACSS/2016. Data collection was done in strict compliance with the Declaration of Helsinki

Consent for publication

Availability of data and materials: The datasets used and/or analysed during the current study are available from the corresponding author on reasonable request.

Competing interests : The authors declare that they have no competing interests

Funding : no funding

Authors' contributions : Conceptualization and methodology: JDDL, GG, SHW; field investigation: JDDL, HSCD ; data verification and analysis: JDDL, SHW, HSCD, GT, GG; draft preparation and writing: all authors

Acknowledgements : the authors of the study thank the National Reference Centre for Sexually Transmitted Diseases and Antiretroviral Therapy of Bangui and the Training Programme in Field and Laboratory Epidemiology in Central Africa respectively for data and material support.

\section{References}

1. UNFPA, UNICEF, WHO, ICF international, World Bank, WFP: Central African Republic: Prevalence of HIV Infection and Associated Factors in the Central African Republic in 2010: Results of the Multiple Indicator Cluster Survey: 2010.

2. Ministry of Health. Central African Republic: National AIDS Strategic Framework, 2016 - 2021: 35-40 p.

3. Grésenguet G, Séhounou J, Bassirou B, Longo JD, Malkin JE, Brogan T, Belec L. Voluntery HIV counselling and testing : experience among the sexually active population in Bangui, Central African Republic. J Acquir Immune Defic Syndr. 2002 Sep 1; 3 (1) :106-14.;

4. Longo JDD, Simaleko MM, Diemer HS-C, Gre'senguet G, Bru“cker G, Belec L (2017) Risk factors for HIV infection among female sex workers in Bangui, Central African Republic. PLoS ONE 12(11): 
e0187654. https://doi.org/10.1371/ journal. pone.0187654

5. Lot F, Pinget R,Cazein F, Pillonel J,Leclerc M, Haguy H, Benyelles L, Semaille C. Frequency and risk factors of inaugural AIDS tuberculosis in France. BEH, mars 2009, 12-13.

6. Yang Z, Kong Y, Wilson F, Foxman B, Fowler AH, Mars CF, et al: Identification of risk factors for extra pulmonary tuberculosis. Clin Infect Dis $2004 ; 38$ :199-205.

7. Moh R, Danel C, Messou E, et al. Incidents and determinants of mortality and morbidity following early antiretroviral therapy initiation in HIV-infected adults in West Africa. AIDS 2007.21:248-249.

8. Poda A, Hema A, Zoungrana J, Kaboré F, Kamboulé E,Bado G, Sawadogo AB. Predictive factors for the occurrence of tuberculosis in HIV-infected adults at the Bobo Dioulasso day hospital, Burkina Faso. Med Mal Infect 2014; 44, (Suppl 6): 28.

9. Dembélé M, Saleri N, Carvalho AC et al, Saoudogo T, Hien A D, Zabsonre I, Koala ST, Simporé S, Matteelli A. Incidence of tuberculosis after initiation of HAART in a cohort of HIV-infected tuberculosis patients in Burkina Faso. Int J Tuberc Lung Dis 2010; 14(3):318-323.

10. Koueta F, Ouedraogo, Dao, Neboua D,Ye D. Tuberculosis in HIV-infected children followed at the Charles de Gaulle Paediatric University Hospital in Ouagadougou, Burkina. J. Mali Médical 2011, Tome XXVI N4.

11. Lawn S D, Myer L, Bekker L G, Wood R. Burden of tuberculosis in an antiretroviral treatment program in sub-Saharan Africa: impact on treatment outcomes and implications for tuberculosis control. AIDS 2006; 20:160-161.

12. Badri M, Wilson D, Wood R. Effect of highly active antiretroviraltherapy on incidence on tuberculosis in South Africa: a cohort study. Lancet 2002;359:205-206.

13. Moore D, Liechty C, Ekwaru P, et al. Prevalence, incidence and mortality associated with tuberculosis in HIV-infected patients initiating antiretroviral therapy in rural Uganda. AIDS 2007; 21:713-719.

14. Foucher $A$, Madec $Y$, Diallo $S$ et al. Incidence and risk factors for tuberculosis in HIV patients on ART in Niger (Summary). www.solthis.org.

15. Bonnet $M$, Pinoges $L$, Varaine $F$, et al. Tuberculosis after HAART initiation in HIV-positive patients from five countries with a high tuberculosis burden. AIDS 2006; 20: 275-279.

16. Seyler C, Messou E, Gabillard D, Inwoley A, Alioum A, Anglaret X. Morbidity before and after HAART initiation in sub-Sahara African HIV-infected adults: recurrent event analysis. AIDS Res Human Retrovir 2007; 23: 1338-1347.

17. Tchaou M, Sonhaye L, Kotosso A et al. Radiographic aspects of the sequelae of tuberculosis in people living with HIV/AIDS in Lomé -Togo. J Fran Viet Pneu 2012; 03(06):1-50.

18. Wateba MI, Diop SA, Salou M, Womitso K, Nichols S, Tidjani O. Negativation of respiratory smears according to HIV status at the intensive phase of anti-tuberculosis treatment in hospitalized patients in Togo. Med Mal Infect 2011; 41: 140-144. 
19. Lawn SD, Evans AJ, Sedgwick PM, Aceampong JW. Pulmonary tuberculosis: radiological features in west Africa coinfected with HIV. The British Journal of radiology 1999;72:339-344.

20. Picon PD, Caramori MLA, Bassanesi SL, Jungblut S, Folgierini M, Porto NS et al. Differences in the tuberculosis in the presence or absence of HIV infection. J Bras Pneumol $2007 ; 33(4): 429-436$.

21. Liberato IRO, Militao de Albuquerque MFP, Campelo ARL, Lacerda de Melon HR. Characteristics of pulmo-nary tuberculosis in HIV seropositive and seronegative patients in a Northwestern region of Brazil. Revista da Sociedade Brasileira de Medecina Tropical 2004 ;37:46-50.

22. Mukadi Y, Perreins J, St Louis M, et al. Spectrum of immunodeficiency in HIV-1-infected patients with pulmonary tuberculosis in Zairre. Lancet $1993 ; 342$ : 143-6

23. Taverne B, Boussairi A, Khuong M and Poupard M. Severity of tuberculosis-HIV co-infection in SeineSaint-Denis. Doi: MEDMAL-06-2013-43-4HS-0399-077X-101019-201209221.

24. Mohamadou S, Ouedraogo E, Dillé I et a/Performance and cost-effectiveness of diagnostic algorithms for pulmonary tuberculosis in people living with HIV in Niamey, Niger. SO8.1(summary).

\section{Tables}

\section{Table Socio-demographic, clinical and para-clinical characteristics of patients and annual 1: $\quad$ incidence of tuberculosis}


Parameters

$\begin{array}{ll}\underset{(\%)}{N u m b e r} & p- \\ \text { value }\end{array}$

TB -

$\mathrm{n}(\%)$

TB+ IR

n (\%)

(\%)ar)

IR by group (\% year)

Age (year)*

\begin{tabular}{|c|c|c|c|c|c|c|}
\hline $18-24$ & $62(09.15)$ & \multirow{6}{*}{0.03} & $51(0.91)$ & $\begin{array}{l}11 \\
(10.58)\end{array}$ & 17.74 & \multirow{3}{*}{15.74} \\
\hline $25-34$ & $\begin{array}{l}284 \\
(41.94)\end{array}$ & & $\begin{array}{l}239 \\
(41.72)\end{array}$ & $\begin{array}{l}45 \\
(43.27)\end{array}$ & 15.84 & \\
\hline $35-44$ & $\begin{array}{l}226 \\
(33.38)\end{array}$ & & $\begin{array}{l}192 \\
(33.51)\end{array}$ & $34(2.70)$ & 15.05 & \\
\hline $45-54$ & 81 (11.97) & & 69 (12.05) & $\begin{array}{l}12 \\
(11.53)\end{array}$ & 14.82 & \multirow{3}{*}{13.33} \\
\hline $55-64$ & $23(3 . .9)$ & & $21(03.66)$ & 2 (1.92) & 8.69 & \\
\hline$\geq 65$ & $1(0.17)$ & & $1(0.17)$ & $0(0.0)$ & 0.0 & \\
\hline
\end{tabular}

Sex

\begin{tabular}{lll} 
Male & 192 & \\
& $(28.36)$ & \multirow{2}{*}{0.35} \\
Female & 485 & \\
& $(71.64)$ &
\end{tabular}

$\begin{array}{llll}156(27.23) & 36(34.62) & 18.75 & 18.75\end{array}$

$\begin{array}{llll}417(72.77) & 68 & 14.02 & 14.02 \\ & (65.38) & & \end{array}$

CD4 rate ${ }^{\star \star}$

\begin{tabular}{|c|c|c|c|c|c|c|}
\hline$\otimes 50$ & $60(08.86)$ & \multirow{3}{*}{0.03} & $53(09.25)$ & 7 (6.73) & 11.66 & \multirow{3}{*}{14.39} \\
\hline $50-199$ & $\begin{array}{l}165 \\
(24.37)\end{array}$ & & $132(23.03)$ & $33(31.73)$ & 0.2 & \\
\hline $200-349$ & $\begin{array}{l}310 \\
(45.79)\end{array}$ & & $273(47.65)$ & $37(35.58)$ & 11.94 & \\
\hline$\geq 350$ & $\begin{array}{l}142 \\
(20.98)\end{array}$ & & $\begin{array}{l}115 \\
(20.07)\end{array}$ & $27(25.96)$ & 19.01 & 19.01 \\
\hline
\end{tabular}

Clinical stage by

WHO ***

\begin{tabular}{|c|c|c|c|c|c|c|}
\hline I & $\begin{array}{l}320 \\
(47.34)\end{array}$ & \multirow{2}{*}{0.02} & $\begin{array}{l}314 \\
(54.80)\end{array}$ & $6(5.77)$ & 1.87 & \multirow{2}{*}{02.82} \\
\hline II & $\begin{array}{l}213 \\
(31.46)\end{array}$ & & $204(35.61)$ & $9(8.65)$ & 4.22 & \\
\hline III & $\begin{array}{l}128 \\
(18.93)\end{array}$ & & $50(08.72)$ & $\begin{array}{l}77 \\
(75.00)\end{array}$ & 60.15 & \multirow{2}{*}{61.80} \\
\hline IV & 16 (2.37) & & $5(0.87)$ & $\begin{array}{l}12 \\
(10.58)\end{array}$ & 75.00 & \\
\hline
\end{tabular}


ARV treatment

\begin{tabular}{|c|c|c|c|c|c|c|}
\hline Yes & $\begin{array}{l}618 \\
(91.28)\end{array}$ & \multirow{2}{*}{0.03} & $537(93.71)$ & $\begin{array}{l}81 \\
(77.88)\end{array}$ & 13.10 & 13.10 \\
\hline No & $59(08.72)$ & & $36(06.28)$ & $\begin{array}{l}23 \\
(22.12)\end{array}$ & 38.99 & 38.99 \\
\hline \multicolumn{7}{|c|}{ Observance ${ }^{\star \star \star \star}$} \\
\hline Good & $\begin{array}{l}657 \\
(97.05)\end{array}$ & \multirow{3}{*}{0.004} & $557(97.21)$ & $\begin{array}{l}100 \\
(96.14)\end{array}$ & 15.22 & 15.22 \\
\hline Medium & $13(1.92)$ & & $11(01.92)$ & $2(01.93)$ & 15.38 & \multirow[b]{2}{*}{23.53} \\
\hline Poor & $7(1.03)$ & & $5(0.87)$ & $2(01.93)$ & 28.57 & \\
\hline \multicolumn{7}{|c|}{$\begin{array}{l}\text { Functional capacity } \\
\star \star \star \star \star \star\end{array}$} \\
\hline Active & $\begin{array}{l}604 \\
(89.21)\end{array}$ & \multirow{3}{*}{0.04} & $566(98.78)$ & $38(36.54)$ & 6.30 & 6.30 \\
\hline Slimming & $70(10.34)$ & & $4(0.69)$ & $\begin{array}{l}66 \\
(63.46)\end{array}$ & 94.28 & \multirow{2}{*}{90.42} \\
\hline Bedridden & $3(0.45)$ & & $3(0.53)$ & $0(0.0)$ & 0.0 & \\
\hline
\end{tabular}

* = p-value for $18-44$ years and $\geq 45$ years

** = p-value for CD4囚350 and CD4囚350/ $\mathrm{mm}^{3}$

$\star \star \star=p$-value for clinical stages group I and II and clinical stages group III and IV of WHO

$* * * *=p$-value for observance group good and observance group medium and poor

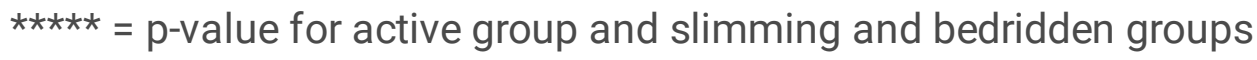

$\mathrm{IR}=$ Incidence rate

Table2: $\quad$ Proportional hazard analysis for factors associated with TB incidence 


\begin{tabular}{|c|c|c|c|c|c|c|c|}
\hline \multirow[t]{2}{*}{ Characteristics } & \multirow{2}{*}{$\begin{array}{l}\text { Number } \\
\text { n (\%) }\end{array}$} & \multirow{2}{*}{$\begin{array}{l}\text { TB+ } \\
n(\%)\end{array}$} & \multirow{2}{*}{$\begin{array}{l}\text { TB- } \\
n(\%)\end{array}$} & \multicolumn{2}{|c|}{ Bivariate analysis } & \multicolumn{2}{|l|}{$\begin{array}{l}\text { Multivariate } \\
\text { analysis }\end{array}$} \\
\hline & & & & $\operatorname{RR}[95 \% \mathrm{Cl}]$ & $\mathrm{p}$ & $\mathrm{RR}_{\mathrm{a}}[95 \% \mathrm{Cl}]$ & $\mathrm{p}$ \\
\hline \multicolumn{8}{|c|}{ Young age (years) } \\
\hline $18-24$ & $\begin{array}{l}62 \\
(17.90)\end{array}$ & $\begin{array}{l}41 \\
(66.13)\end{array}$ & $\begin{array}{l}18 \\
(29.03)\end{array}$ & - & & - & - \\
\hline $25-30$ & $\begin{array}{l}284 \\
(82.10)\end{array}$ & $\begin{array}{l}31 \\
(10.92)\end{array}$ & $\begin{array}{l}255 \\
(89.79)\end{array}$ & $\begin{array}{l}18.73[9.60- \\
36.53]\end{array}$ & $<0.001$ & $\begin{array}{l}1.10[0.80- \\
1.57]\end{array}$ & ** \\
\hline \multicolumn{8}{|l|}{ Older age (years) } \\
\hline $31-44$ & $\begin{array}{l}226 \\
(68.27)\end{array}$ & $\begin{array}{l}27 \\
(11.95)\end{array}$ & $\begin{array}{l}204 \\
(90.27)\end{array}$ & - & & - & - \\
\hline 45 et plus & $\begin{array}{l}105 \\
(31.73)\end{array}$ & $\begin{array}{l}5 \\
(4.76)\end{array}$ & $\begin{array}{l}96 \\
(91.43)\end{array}$ & $\begin{array}{l}2.54[0.94- \\
6.80]\end{array}$ & 0.057 & - & - \\
\hline \multicolumn{8}{|l|}{ Sex } \\
\hline Male & $\begin{array}{l}192 \\
(28.36)\end{array}$ & $\begin{array}{l}26 \\
(13.54)\end{array}$ & $\begin{array}{l}166 \\
(86.46)\end{array}$ & - & & - & - \\
\hline Female & $\begin{array}{l}485 \\
(71.64)\end{array}$ & $\begin{array}{l}78 \\
(16.08)\end{array}$ & $\begin{array}{l}407 \\
(83.92)\end{array}$ & $\begin{array}{l}0.81[0.50- \\
1.31]\end{array}$ & 0.47 & - & - \\
\hline \multicolumn{8}{|l|}{ CD4 rate } \\
\hline$<350$ & $\begin{array}{l}535 \\
(79.02)\end{array}$ & $\begin{array}{l}92 \\
(17.20)\end{array}$ & $\begin{array}{l}443 \\
(82.80)\end{array}$ & - & & - & \\
\hline$\geq 350$ & $\begin{array}{l}142 \\
(20.98)\end{array}$ & $\begin{array}{l}12 \\
(8.45)\end{array}$ & $\begin{array}{l}130 \\
(91.55)\end{array}$ & $\begin{array}{l}2.24[1,19- \\
4.23]\end{array}$ & 0.012 & $\begin{array}{l}3.20[1.81- \\
5.90]\end{array}$ & $\star \star * *$ \\
\hline \multicolumn{8}{|c|}{ Clinical stage by WHO } \\
\hline$|\&| \mid$ & $\begin{array}{l}433 \\
(63.96)\end{array}$ & $\begin{array}{l}31 \\
(7.16)\end{array}$ & $\begin{array}{l}402 \\
(92.84)\end{array}$ & - & & - & \\
\hline III \& IV & $\begin{array}{l}244 \\
(36.04)\end{array}$ & $\begin{array}{l}73 \\
(29.92)\end{array}$ & $\begin{array}{l}171 \\
(70.08)\end{array}$ & $\begin{array}{l}0.18[0.11- \\
0.28]\end{array}$ & $<0.001$ & $\begin{array}{l}0.55[0.40- \\
0.75]\end{array}$ & **** \\
\hline \multicolumn{8}{|l|}{ ARV treatment } \\
\hline Before ART & $\begin{array}{l}218 \\
(32.20)\end{array}$ & $\begin{array}{l}91 \\
(41.74)\end{array}$ & $\begin{array}{l}127 \\
(58.26)\end{array}$ & - & & - & \\
\hline ART & $\begin{array}{l}459 \\
(67.80)\end{array}$ & $\begin{array}{l}13 \\
(2.83)\end{array}$ & $\begin{array}{l}446 \\
(97.17)\end{array}$ & $\begin{array}{l}24.58[13.30- \\
45.40]\end{array}$ & $<0.001$ & $\begin{array}{l}7.56[2.12- \\
26.96]\end{array}$ & $\star \star \star *$ \\
\hline \multicolumn{8}{|l|}{ Observance } \\
\hline Good & $\begin{array}{l}459 \\
(67.80)\end{array}$ & $\begin{array}{l}33 \\
(7.04)\end{array}$ & $\begin{array}{l}426 \\
(90.83)\end{array}$ & - & & - & - \\
\hline
\end{tabular}




\begin{tabular}{|c|c|c|c|c|c|c|c|}
\hline Medium/Poor & $\begin{array}{l}218 \\
(32.20)\end{array}$ & $\begin{array}{l}71 \\
(32.57)\end{array}$ & $\begin{array}{l}147 \\
(67.43)\end{array}$ & $\begin{array}{l}0.16[0.10- \\
0,25]\end{array}$ & $<0,001$ & $\begin{array}{l}0,92[0,62- \\
1,38]\end{array}$ & ** \\
\hline \multicolumn{8}{|c|}{ Capacité fonctionnelle } \\
\hline Active & $\begin{array}{l}504 \\
(74,44)\end{array}$ & $\begin{array}{l}28 \\
(5,56)\end{array}$ & $\begin{array}{l}476 \\
(94,44)\end{array}$ & - & & - & \\
\hline Grabataire & $\begin{array}{l}173 \\
(25,56)\end{array}$ & $\begin{array}{l}76 \\
(43,93)\end{array}$ & $\begin{array}{l}97 \\
(56,07)\end{array}$ & $\begin{array}{l}0,07[0,04- \\
0.12]\end{array}$ & $<0.001$ & $\begin{array}{l}0.15[0.12- \\
0.95]\end{array}$ & *** \\
\hline
\end{tabular}

RR= Risk Ratio ; RRa = Adjusted Risk Ratio ; 95\% Cl= Confidence Interval 95\%; $p=p$-value ; ; $* \star \star *=0.001$ $; * \star \star=p<0.05 ; * \star=p>0.05$

\section{Figures}

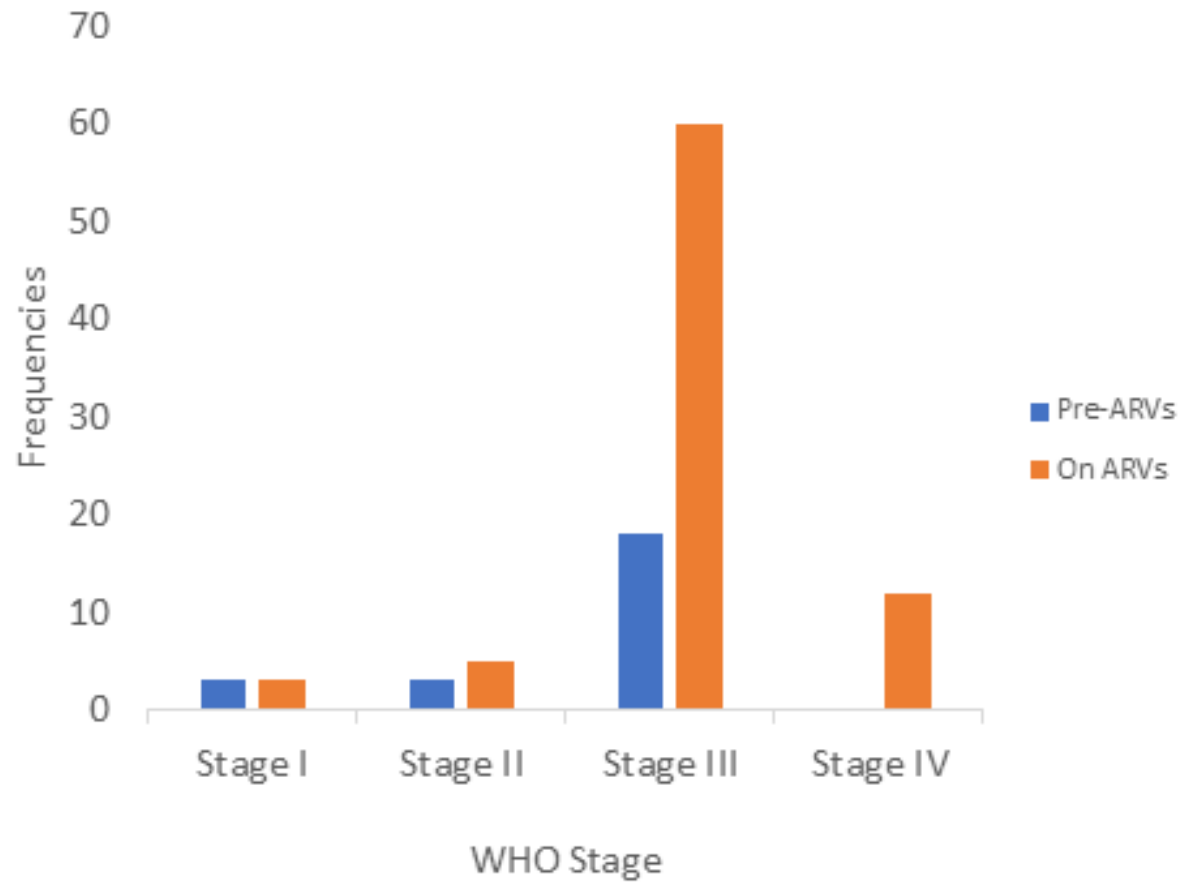

Figure 1

Trends in the occurrence of TB according to WHO stage 


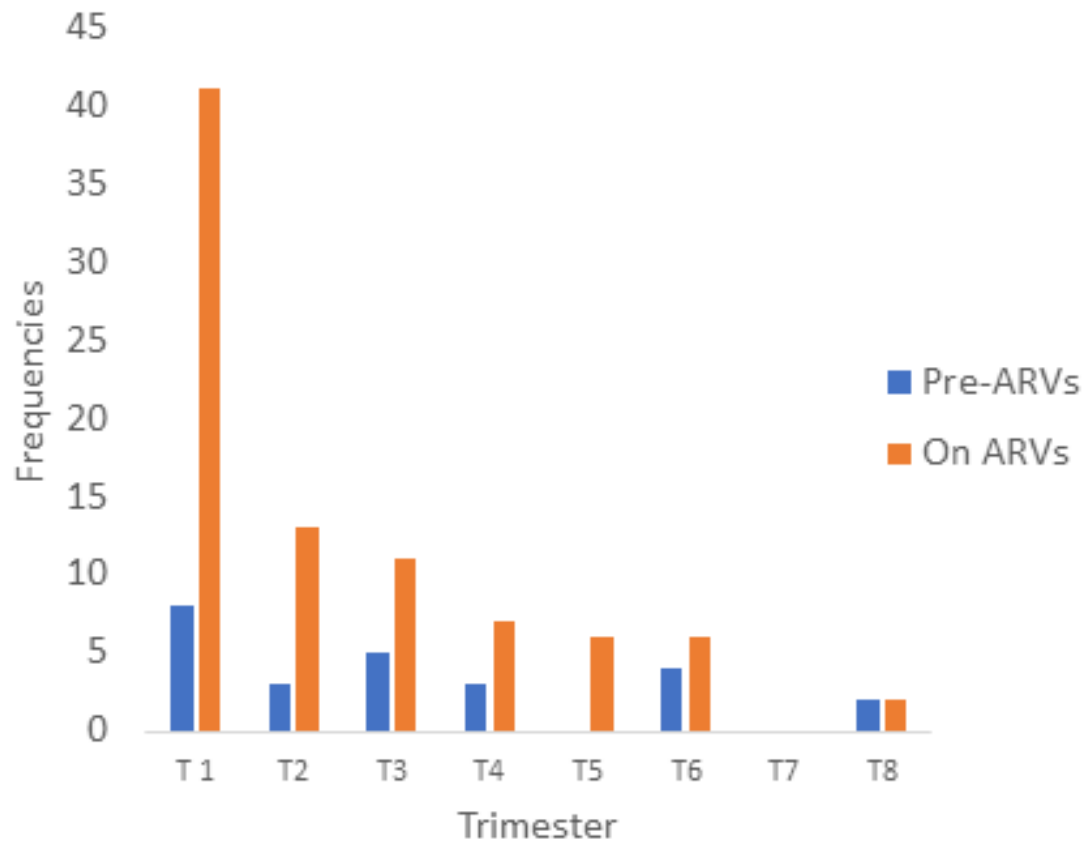

Figure 2

TB cases by quarter and ARV status 